\title{
Percepção Socioambiental: o Projeto Canecas e o Programa de Coleta Seletiva Solidária da Universidade Federal de São Carlos, São Paulo, Brasil
}

\author{
Socio-Environmental Perception: the Canecas Project and the Solidary Selective Waste \\ Collection Program At the Federal University of São Carlos, São Paulo, Brazil
}

\section{Percepción Socioambiental: el Proyecto Canecas y el Programa de Recogida Selectiva Solidária Em la Universidad Federal de São Carlos, São Paulo, Brasil}

\author{
Silvia Helena Flamini ${ }^{1}$ \\ Liane Biehl Printes ${ }^{2}$
}

\begin{abstract}
Resumo
A Revolução Industrial estabeleceu um novo tipo de relação do homem com o meio ambiente, incorporando na vida e na cultura conceitos como o contínuo crescimento econômico, o consumo e a necessidade de gerar excedentes. Nos últimos anos, evidenciou-se o aumento no volume de resíduos sólidos decorrentes das atividades humanas. Na Universidade Federal de São Carlos (UFSCar), campus São Carlos, são desenvolvidas práticas educativas que tratam da problemática dos resíduos para despertar a sensibilidade ambiental da comunidade acadêmica. A investigação sobre o envolvimento e o interesse dos alunos nessas atividades justifica a aplicação da metodologia utilizada neste trabalho, que consistiu em entrevistas estruturadas por dois questionários simples, com os objetivos de estimar a intensidade do uso das canecas permanentes e a efetividade do Projeto Canecas, bem como de avaliar a participação dos alunos nas ações do Programa Coleta Seletiva Solidária da UFSCar. Os resultados mostram que a adesão ao uso das canecas no ambiente universitário é majoritária, sendo o projeto uma importante colaboração para a redução da geração de resíduos de copos descartáveis, mas de moderada contribuição em relação à formação ambiental, pois se observa a ausência de motivação pessoal em relação à utilização da caneca por parte dos entrevistados. Verifica-se também o desinteresse da comunidade estudantil no que tange às ações do Programa Coleta Seletiva Solidária UFSCar. Assim sendo, é necessário a instituição reforçar o estímulo para a promoção da sensibilização e percepção ambientais pela comunidade acadêmica envolvida.
\end{abstract}

Palavras-chave: Resíduos sólidos. Educação ambiental. Projeto Canecas. Coleta seletiva.

\begin{abstract}
The Industrial Revolution established a new type of relationship between man and the environment. It has incorporated some concepts such as the continuous economic growth; consumption and need for surplus generation into the life and culture. In this context, an increase of solid wastes represented by the leftovers of human activities was observed. Educational practices have been developed at the Federal University of São Carlos (UFSCar), São Carlos Campus, to deal with the problem of solid waste and also to awake the environmental sensitivity of the academic community. The investigation on the UFSCar students' engagement in these activities justify the application of the methodology used in this work, which consisted of structured interviews composed of two simple questionnaires. The objective was to quantify the use of durable mugs as an indicator of effectiveness of the Canecas Project - replacement of disposable plastic cups by durable mugs, and the engagement in the actions of the Solidary Selective Waste Collection Program at the Federal University of São Carlos (PCSSU). The results showed that most of the community adhered to the use of mugs in the university environment, and this project has an important contribution to the reduction of waste generation, but moderate contribution when it comes to environmental awareness. Thus, there is an absence of personal motivation considering the use of the mugs by some of the interviewees. The findings also showed that there is a lack of interest from the student community regarding the Solidary Selective Waste Collection Program at UFSCar. Therefore, the institution should permanently promote environmental awareness and perception to the academic community.
\end{abstract}

\footnotetext{
${ }^{1}$ A autora é bacharela em Ciências Biológicas pela Universidade Federal de São Carlos (UFSCar), Brasil, e mestranda do Programa de Pós-Graduação em Ciência, Tecnologia e Sociedade (PPGCTS) da mesma instituição.

${ }^{2}$ A autora é doutora em Biologia Animal pela University Of Reading, Grã-Bretanha. Biólogo - Técnico de Nível Superior da Universidade Federal de São Carlos (UFSCar), Brasil.
} 
Keywords: Solid waste. Environmental education. Canecas Project. Selective collect.

\begin{abstract}
Resumen
La revolución industrial estableció un nuevo tipo de relación del hombre con el medio ambiente, incorporando en la vida y en la cultura conceptos como el continuo crecimiento económico, el consumo y la necesidad de generar excedentes. Se comprueba, por tanto, un aumento en el volumen de residuos sólidos resultantes de las actividades humanas. En la Universidad Federal de São Carlos (UFSCar), campus São Carlos, se desarrollan prácticas educativas que tratan tanto de la problemática de estos residuos como también de la sensibilización ambiental de la comunidad académica. La investigación sobre la participación y el interés de los alumnos en estas actividades justifica la aplicación de la metodología utilizada en este trabajo, que consistió en entrevistas estructuradas compuestas por dos cuestionarios simples, con los objetivos de estimar la efectividad del "Proyecto Canecas" y la intensidad del uso de las tazas personales no desechables, así como evaluar la participación de los alumnos en las acciones del Programa Recogida Selectiva Solidaria de la UFSCar. Los resultados muestran que la adhesión al uso de las tazas en el ambiente universitario es mayoritaria, así que el proyecto es una importante contribución para la reducción de la generación de residuos de vasos desechables, pero de moderada contribución con relación a la formación ambiental, pues se observa una ausencia de motivación personal respecto a la utilización de la taza por una parte de los entrevistados. Se observa también un desinterés de la comunidad estudiantil en lo que se refiere al Programa Recogida Selectiva Solidaria UFSCar. Por lo tanto, es necesario un estímulo constante por parte de las instituciones universitarias, para aumentar sensibilización y la percepción ambiental de toda la comunidad académica.
\end{abstract}

Palabras clave: Residuos sólidos. Educación ambiental. Proyecto Canecas. Recogida selectiva.

\title{
1 Introdução geral
}

O ser humano é diretamente vinculado ao meio ambiente (MAKIUCHI, 2005) e, no decorrer de sua trajetória sobre o planeta, impôs ao ecossistema diversas transformações que foram capazes de viabilizar a sobrevivência e a persistência da espécie na Terra (SIQUEIRA, 2002).

Com a Revolução Industrial no século XIX, difundiu-se a concepção de que uma nova relação do homem com seu ambiente deveria ser estabelecida. Conceitos como a geração excedente e o contínuo crescimento econômico com dominação de novas fronteiras foram incorporados na vida e cultura da civilização pós-industrial; disto resultou uma mudança nos padrões do elo homem-ambiente (SIQUEIRA, 2002).

Evidenciou-se, com tal revolução e seu método de produção mais eficiente, o aumento no volume de resíduos sólidos, sendo os produtos fabricados de forma mais rápida e barata, estimulando indiretamente o consumo (HEMPE; NOGUERA, 2012).

Segundo Logarezzi (2016), resíduo é o que sobra de uma atividade humana qualquer, natural ou cultural. De modo geral, geramos resíduos e não lixo, sendo esta categoria ampla e incluindo material, ou substância, nos estados sólido ou semissólido, bem como gases, líquidos e outros compostos gerados nos mais diversos campos de atividades (BRASIL, 2010).

As mudanças notoriamente profundas no comportamento social relacionadas ao consumo também foram desencadeadas nas décadas de 1940 e 1950, principalmente devido ao acelerado desenvolvimento capitalista no pós-guerra. Tal desenvolvimento se deu, sobretudo, nos países industrializados, influenciados pelo modelo estadunidense consumista denominado "american way of life" e de incentivo à geração de produtos descartáveis e de materiais sintéticos. Com o crescente desenvolvimento na indústria alimentícia e a incorporação de novos hábitos alimentares, ocorreu a produção gradativa de embalagens compostas por diferentes tipos de materiais, principalmente plásticos, metais e alumínio (LEITE, 2005). Segundo Hempe e Noguera (2012), o aumento dos resíduos sólidos urbanos também resultou do crescimento populacional, além do consumo, sendo este dependente de outros fatores, como época e atividades econômicas e culturais. 
Embora a década de 1970 seja igualmente marcada pelo aumento da liberação desses resíduos através de práticas exploratórias da natureza, do desenvolvimento de novas tecnologias e pelo permanente incentivo ao consumismo (SOBARZO; MARIN, 2010), vários segmentos sociais já demonstravam preocupação com a crescente deterioração ambiental e o esgotamento de recursos (SIQUEIRA, 2002).

No ano de 1972, ocorreu a Conferência Internacional para o Meio Ambiente Humano (United Nations Conference on the Human Environment [UNCHE]), promovida pela Organização das Nações Unidas (ONU) na Suécia. No evento, foram abordadas, pela primeira vez, questões pertinentes ao meio ambiente e ao desenvolvimento (PORTO-GONÇALVES, 2006).

Nos anos de 1990, as questões ambientais atingiram tamanha visibilidade após a Conferência das Nações Unidas sobre Meio Ambiente e Desenvolvimento, conhecida como Rio-92, que o questionamento ambiental passou a ser tema obrigatório na agenda política (PORTO-GONÇALVES, 2006). Deste encontro resultou a Agenda 21, programa de ação abrangente que visava à sustentabilidade global no século XXI (GRANZOTTO; PRETTO, 2012).

Os compromissos da Agenda 21 foram reafirmados no ano de 2002, na Cúpula da Terra sobre Desenvolvimento Sustentável, também conhecida como RIO+10. Este fórum ocorreu em Joanesburgo, na África do Sul, e propôs a preservação e o cuidado com o meio ambiente, relacionando-o a aspectos sociais. Também se discutiu a integração entre as dimensões econômica, social e ambiental conciliadas ao desenvolvimento sustentável (GRANZOTTO; PRETTO, 2012).

Uma década após o evento Rio+10, ocorreu, no Rio de Janeiro, a Conferência das Nações Unidas sobre o Desenvolvimento Sustentável, ou Rio+20. Embora não tenha produzido avanço significativo no que se refere à Rio-92, tal convocação reviveu as esperanças em relação ao avanço na transição para uma sociedade global sustentável (GUIMARÃES; FONTOURA, 2012).

Houve, portanto, a popularização da discussão sobre os impactos do desenvolvimento nos ecossistemas e na saúde dos indivíduos. Desde então, são almejados mecanismos que atenuem a pressão exercida sobre o meio ambiente pela sociedade, de modo a garantir a sobrevivência da vida no planeta (GOUVEIA, 2012).

A geração de resíduos envolve etapas distintas que compreendem a extração da matériaprima na natureza, a produção, a comercialização, o consumo e o posterior descarte (SOBARZO; MARIN, 2010). Deste modo, a problemática dos resíduos sólidos adquiriu relevância na sociedade moderna, em termos de quantidade e diversidade.

Vale destacar que, nos custos de produção e consumo, não estão inseridos o uso, o esgotamento e a degradação dos recursos ambientais que são decorrentes de padrões insustentáveis (FERREIRA, 2005). Além disso, os resíduos gerados, subprodutos das atividades humanas resultantes do atual modelo capitalista, ultrapassaram a capacidade de adaptação da natureza, que não mais incorpora por completo esses elementos em seus ciclos ambientais originais (SIQUEIRA, 2002).

O conhecimento das propriedades, assim como das características dos resíduos gerados, é de notória importância para o seu bom gerenciamento (HEMP; NOGUERA, 2012). É de responsabilidade pública o gerenciamento adequado de tais resíduos e a atuação de todos para que a minimização dos impactos ambientais seja alcançada (RAMOS; DELL'ISOLA, 2010).

As instituições de ensino superior (IES) possuem papel fundamental, neste sentido, pois proporcionam conhecimentos e tecnologias, aprofundando o senso crítico dos acadêmicos, que exercem influências na comunidade em que atuam por meio das ações sociais (GRANZOTTO; PRETTO, 2012). Destaca-se que é por meio da educação que as universidades contribuem na qualificação de seus egressos e futuros tomadores de decisão (TAUCHEN; BRANDLI, 2006). 
Como possibilidade de motivação e de sensibilização destinada a transformar as diferentes formas de participação na defesa da qualidade de vida, há a educação voltada para cidadania e, nesse sentido, vale destacar a Educação Ambiental (EA) e sua função transformadora no que tange à compreensão da relação humana com seu entorno (JACOBI, 2004; SPAZZIANI; GONÇALVES, 2005).

A prática educativa, numa EA crítica, é a formação humana enquanto ser individual e social situado historicamente, considerando o ambiente como o conjunto das inter-relações estabelecidas entre os mundos natural e social. Seguida da ação emancipatória no campo ambiental e mediada por saberes locais, tradicionais e científicos, ela deve articular a compreensão dos problemas socioambientais nas suas múltiplas dimensões: geográficas, históricas, biológicas, sociais e também subjetivas (CARVALHO, 2004).

As instituições de ensino superior também devem incorporar os princípios e práticas da sustentabilidade, de modo a contribuir para a construção do desenvolvimento de uma sociedade justa e sustentável (TAUCHEN; BRANDLI, 2006). Desta maneira, destaca-se que a consolidação de grupos de estudo e pesquisa podem contribuir para o incremento da prática e da reflexão na EA.

No Estatuto da Universidade Federal de São Carlos (UFSCar) constam, no artigo $2^{\circ}$, a sustentabilidade e a responsabilidade ambiental como princípios da instituição; também se pode destacar como objetivo, de acordo com artigo $4^{\circ}$, o estudo dos problemas sociais, econômicos e ambientais oriundos da sociedade, com a finalidade de apresentar soluções mediante exercício da democracia (UNIVERSIDADE FEDERAL DE SÃO CARLOS, 1990).

Deste modo, são desenvolvidas, no campus São Carlos, práticas educativas que tratam da problemática dos resíduos sólidos e que visam despertar a sensibilidade ambiental da comunidade acadêmica. Dentre as atividades desenvolvidas, estão o Projeto Canecas e o Programa de Coleta Seletiva Solidária UFSCar, em consonância com o Decreto Federal $n^{\circ}$ 5.940/2006 e vinculados aos Departamentos de Apoio à Educação Ambiental (DeAEA) e de Gestão de Resíduos (DeGR).

As atividades citadas são objetos de estudo do presente trabalho, que possui os seguintes propósitos: estimar a intensidade do uso das canecas permanentes e a efetividade do Projeto Canecas em relação aos seus objetivos - redução na utilização de copos descartáveis e diminuição da produção de resíduos pelo restaurante universitário (RU), bem como estímulo para a reflexão acerca das práticas de consumo pessoais dos envolvidos. Além disso, este trabalho pretende avaliar a participação dos discentes nas ações do Programa Coleta Seletiva Solidária UFSCar, destacando a contribuição de tais ações para a aquisição da sensibilidade ambiental pela comunidade acadêmica.

\subsection{Histórico das atividades}

\subsubsection{O Projeto Canecas}

O projeto é responsável pela distribuição de canecas às(aos) calouras(os) e novas(os) integrantes da comunidade acadêmica em todos os campi da instituição e possui dois objetivos: o primeiro corresponde à redução na utilização e, consequentemente, à diminuição da produção de resíduos de copos descartáveis pelo restaurante universitário da UFSCar; o segundo é o estímulo da reflexão acerca das práticas de consumo pessoais dos envolvidos. É realizado todos os anos pelo Departamento de Apoio à Educação Ambiental (DeAEA), com apoio das PróReitorias de Assuntos Comunitários e Estudantis (ProACE) e de Extensão (ProEx), sendo a ProACE responsável pela compra das canecas.

Seu início foi concebido pela iniciativa de um extinto grupo estudantil da universidade, chamado Grupo Ambiental Ipê Amarelo (Gaia), no ano de 2003, contando com a parceria do 
restaurante universitário que, à época, passou a disponibilizar copos descartáveis apenas aos visitantes.

Em 2010, foi incorporado como atividade permanente ao Programa de Atividades de Extensão da antiga e extinta Coordenadoria Especial para o Meio Ambiente (Cema). No ano subsequente, dois outros grupos estudantis aderiram ao projeto: o Grupo de Incentivo à Redução, Reutilização e Reciclagem (Gire) e Empresa Júnior da Biologia (EMA-BIO). Esses grupos estudantis auxiliam na organização dos eventos de entrega e na distribuição das canecas.

Os eventos de entrega ocorrem no início do primeiro semestre letivo. Atualmente, possuem a duração de aproximadamente trinta minutos, com a realização de uma palestra rápida de abertura, geralmente para apresentar os grupos estudantis envolvidos na distribuição das canecas, além da exibição de um curta-metragem sobre a problemática ambiental em relação aos resíduos sólidos gerados. Projeto $^{3}$

O curta-metragem foi elaborado pelos integrantes do Gaia, no início da implantação do

Nos últimos oito anos do projeto, foram distribuídas 15.874 canecas aos ingressantes da comunidade acadêmica.

\subsubsection{Coleta seletiva na UFSCar}

Na década de 1990, foi implantada a coleta seletiva na UFSCar, sendo a universidade pioneira na separação de resíduos na cidade de São Carlos. Além da realização de uma campanha de sensibilização, foi construído um Local de Entrega Voluntária (LEV) dos resíduos e, assim, a universidade tornou-se centro de referência para a coleta seletiva na cidade e em sua região.

A implantação da coleta seletiva no município de São Carlos ocorreu no ano de 2004, através de um programa envolvendo cooperativas de catadores. A partir do mesmo ano, a universidade passou a participar do programa municipal, com a desativação do LEV.

O Decreto Federal n ${ }^{\circ} 5.940$, que entrou em vigor no dia 25 de outubro de 2006 (BRASIL, 2006), instituiu a separação e a destinação dos resíduos recicláveis gerados pelos órgãos e entidades da administração pública federal direta ou indiretamente, às associações e cooperativas de catadores.

Em 2011, houve a aprovação da portaria interna GR 10, de outubro de 2011, adequando a coleta seletiva da instituição aos termos do Decreto. Deste modo, a coleta foi efetivada como Programa Permanente de Gestão e Gerenciamento Compartilhado de Resíduos Sólidos e Coleta Seletiva Solidária. No mesmo ano foram distribuídos, no campus de São Carlos, coletores amarelos destinados ao descarte seletivo de materiais (plásticos, vidros e metais) no interior dos prédios e departamentos, bem como novas caixinhas coletoras de papel (utilizadas desde 2003). Como as cooperativas que coletam os materiais recicláveis na UFSCar fazem a segregação dos materiais pós-coleta, não há necessidade de segregação por tipo no momento do descarte. Assim, todos os materiais recicláveis são descartados em um único coletor. A diferenciação de cor é apenas para auxiliar na distinção entre o coletor de recicláveis do de não recicláveis.

Os primeiros 25 contentores destinados à estocagem de materiais recicláveis e adquiridos com verba administrativa foram distribuídos no campus de São Carlos no início do ano 2012, sendo os pontos de coleta predefinidos pela comunidade acadêmica em 2010, por meio de entrevistas. Optamos por uma única cor para representar a coleta seletiva. $O$ azul foi escolhido por ser a cor utilizada na representação do papel na coleta (BRASIL, 2001), uma vez que o papel é o principal componente dos resíduos recicláveis na UFSCar. Posteriormente, os

\footnotetext{
${ }^{3}$ Ele pode ser encontrado no endereço https://bit.ly/2VKLr63.
} 
campi de Araras e Sorocaba também receberam tais contentores (A COLETA SELETIVA, 2016). Atualmente, são 31 pontos e 35 contentores distribuídos no campus São Carlos.

\subsection{3 $1^{a}$ Semana do Lixo Mínimo}

Dentre as ações educativas realizadas pelo Programa Permanente de Gestão e Gerenciamento Compartilhado de Resíduos Sólidos e Coleta Seletiva Solidária, a $1^{\text {a }}$ Semana do Lixo Mínimo ocorreu entre os dias 17 e 21 de agosto de 2015. A semana, coordenada pelo Departamento de Apoio à Educação Ambiental (DeAEA), foi inspirada na Semana Campus Lixo Zero realizada pela Universidade Federal de Santa Catarina (UFSC), que acontece entre os dias 3 e 7 de novembro de 2014. Na UFSCar, o evento teve como objetivos: fornecer informações sobre o assunto, proporcionar aos participantes a reflexão e o debate sobre a exacerbada produção de resíduos e seus impactos negativos ao meio ambiente e na qualidade de vida, bem como partilhar experiências e conhecimentos entre os envolvidos, além de estimular as práticas de redução e reutilização, ressaltando também a importância da gestão e do correto encaminhamento dos resíduos recicláveis e orgânicos.

\subsubsection{Feira de trocas}

É outra prática de sensibilização que ocorreu pela primeira vez na $1^{\text {a }}$ Semana do Lixo Mínimo, sendo posteriormente realizada toda última quarta-feira do mês, durante o período do almoço. O local escolhido para o acontecimento foi uma área destinada a eventos acadêmicos, no Diretório Central de Estudantes (DCE), chamada Palquinho da UFSCar. No mesmo local, ocorre a Feira de Economia Solidária, promovida pelo Núcleo de Economia Solidária (NuMI Eco-Sol). Assim, os dois eventos podem se fortalecer mutuamente.

A ideia da feira foi promover um espaço para o estímulo da troca, reutilização e, consequentemente, redução no consumo.

\section{Material e métodos}

Para este estudo, foram realizadas entrevistas estruturadas compostas por dois questionários simples com o intuito de obter um considerável número de participantes. $\mathrm{O}$ público-alvo das pesquisas foi a comunidade acadêmica estudantil da UFSCar, dos cursos presenciais, no campus de São Carlos-SP.

O primeiro questionário, composto por cinco questões de múltipla escolha, tinha como objetivo avaliar qualitativa e quantitativamente o uso de canecas permanentes pelos estudantes, incluindo o uso das canecas UFSCar recebidas pelo Projeto Canecas. Ele foi aplicado aos alunos ingressantes dos anos de 2010, 2011, 2012, 2013, 2014, 2015 e 2016.

O segundo questionário, também composto por questões de múltipla escolha com dois tópicos, tinha como objetivo verificar o motivo da escassa participação estudantil nos eventos de educação ambiental ocorridos no campus: $1^{\text {a }}$ Semana do Lixo Mínimo e Feira de Trocas.

Além da realização das entrevistas, também foram utilizados relatórios anuais do Projeto Canecas, que constam no ProexWeb, e comunicação pessoal por meio de entrevistas e da experiência pessoal de estágio no Departamento de Apoio à Educação Ambiental (DeaEA).

\section{Resultados e discussão}

\subsection{O Projeto Canecas}


Por meio da aplicação do primeiro questionário, foram entrevistados 529 estudantes dos cursos de graduação da UFSCar, divididos em três áreas de estudo: Ciências Exatas e de Tecnologia, Ciências Biológicas e da Saúde, e Educação e Ciências Humanas.

O objetivo da primeira pergunta foi verificar a utilização de canecas permanentes pela comunidade acadêmica estudantil durante sua permanência na instituição. Na Tabela 1, observa-se que 480 entrevistados (91\%) das áreas de conhecimento utilizam as canecas duráveis no ambiente acadêmico e que 49 entrevistados (9\%) responderam não a usar na universidade.

Tabela 1 - Número e percentual de entrevistados por área acadêmica quanto ao uso, ou não, de canecas no ambiente acadêmico

\begin{tabular}{|c|c|c|c|c|}
\hline & $\begin{array}{l}\text { Ciências } \\
\text { Exatas e de } \\
\text { Tecnologia }\end{array}$ & $\begin{array}{l}\text { Ciências } \\
\text { Biológicas e } \\
\text { da Saúde }\end{array}$ & $\begin{array}{l}\text { Educação e } \\
\text { Ciências } \\
\text { Humanas }\end{array}$ & Total \\
\hline $\begin{array}{l}\text { Número de alunos } \\
\text { Sim } \\
\text { Não }\end{array}$ & $\begin{array}{l}228 \\
26\end{array}$ & $\begin{array}{l}150 \\
14\end{array}$ & $\begin{array}{l}102 \\
9\end{array}$ & $\begin{array}{l}480 \\
49\end{array}$ \\
\hline $\begin{array}{ll}\text { Percentual } & \text { de } \\
\text { alunos } & \\
\text { Sim } & \\
\text { Não } & \end{array}$ & $\begin{array}{l}90 \\
10\end{array}$ & $\begin{array}{l}91 \\
9\end{array}$ & $\begin{array}{l}92 \\
8\end{array}$ & $\begin{array}{l}91 \\
9\end{array}$ \\
\hline
\end{tabular}

Ressalta-se que, desde o ano de 2003, o restaurante universitário não mais disponibiliza copos plásticos aos seus usuários, com o objetivo de estimular a adoção das canecas. Portanto, na ausência dessas ou de outro recipiente, não é possível o consumo de líquidos no restaurante.

É importante destacar também que as lanchonetes do campus ainda disponibilizam copos descartáveis aos consumidores e que a inexistência de parceria entre a UFSCar e tais lanchonetes, neste sentido, associada à ausência de outras formas de incentivo ao uso da caneca dentro ou fora do ambiente institucional, desestimula o uso da caneca. Sendo assim, a utilização da caneca pelos alunos na universidade fica restrita ao RU e a bebedouros; ou, eventualmente, a alguma festividade estudantil no campus. No último caso, fica a critério dos organizadores solicitar que os participantes levem a caneca para o evento.

Apesar disso, a adesão ao uso das canecas no ambiente universitário é majoritária e, com isso, o projeto constitui importante contribuição para a redução da geração de resíduos durante a permanência estudantil no ambiente acadêmico. Nesse sentido, é fundamental que a UFSCar realize uma parceria com as lanchonetes do campus, o que resultará no compromisso dos estudantes com o projeto, possibilitando a vivência dos objetivos no cotidiano dos envolvidos.

O objetivo da segunda pergunta foi verificar se os estudantes fazem uso cotidiano da caneca permanente. Observa-se, na Tabela 2, que 397 alunos (75\%) responderam fazer uso diário dela e que 132 entrevistados $(25 \%)$ responderam não a utilizar diariamente.

Tabela 2 - Número e percentual de entrevistados por área acadêmica quanto ao uso cotidiano de canecas duráveis

\begin{tabular}{|l|l|ll|l} 
Ciências & $\mid \begin{array}{l}\text { Ciências } \\
\text { Exatas e de ducação e e } \\
\text { Tecnologia }\end{array}$ & $\begin{array}{l}\text { Biológicas e da } \\
\text { Saúde }\end{array}$ & $\begin{array}{l}\text { Ciências } \\
\text { Humanas }\end{array}$ & Total
\end{tabular}




\begin{tabular}{|c|c|c|c|c|}
\hline $\begin{array}{l}\text { Número de alunos } \\
\text { Sim } \\
\text { Não }\end{array}$ & $\begin{array}{l}186 \\
\end{array} 68$ & 120 & $\begin{array}{l}91 \\
20\end{array}$ & $\begin{array}{l}397 \\
132\end{array}$ \\
\hline $\begin{array}{l}\text { Percentual de } \\
\text { alunos }\end{array}$ & & & & \\
\hline Sim & 73 & 73 & 82 & 75 \\
\hline Não & 27 & 27 & 18 & 25 \\
\hline
\end{tabular}

A utilização diária da caneca apresenta porcentagens menores quando comparada ao uso na universidade (Tabela 1).

Pode-se pressupor que, para parte dos alunos, o uso da caneca durável na instituição é induzido pela obrigatoriedade imposta pelo RU. Assim, embora seja efetivo, esse mecanismo também é punitivo, devido à impossibilidade de consumir líquidos sem a caneca. Pode-se inferir que a norma utilizada pelo restaurante reflete os resultados apresentados nas Tabelas 1 e 2, isto é, que grande parte dos entrevistados respondeu utilizar a caneca no ambiente acadêmico e diariamente.

Os usuários, então, são como que forçados a utilizar a caneca no restaurante, o que sugere que há ausência de motivação pessoal no que tange ao seu uso.

Entretanto, é importante ressaltar que a medida empregada pelo restaurante também contribui para que o primeiro objetivo do projeto seja alcançado, ou seja, a redução na utilização de copos descartáveis e a diminuição da produção de resíduos pelo RU. Isso representa um ganho econômico para a universidade, que reduz a compra de copos plásticos, podendo investir em outras questões relevantes para a instituição, além de gerenciar uma menor quantidade de resíduos (PRADO et al., 2012).

A Tabela 3 mostra que 340 entrevistados (64\%) responderam usar a caneca retornável em festas ou eventos. Por outro lado, 189 alunos (36\%) não as utilizam nessas situações.

Tabela 3 - Número e percentual de entrevistados por área acadêmica quanto ao uso da caneca para outros fins (festas e/ou eventos)

\begin{tabular}{c|l|l|l|l} 
& $\begin{array}{l}\text { Ciências } \\
\text { Exatas e de } \\
\text { Tecnologia }\end{array}$ & $\begin{array}{l}\text { Ciências } \\
\text { Biológicas e da } \\
\text { Saúde }\end{array}$ & $\begin{array}{l}\text { Educação } \\
\text { Ciências } \\
\text { Humanas }\end{array}$ & Total \\
\hline $\begin{array}{c}\text { Número de alunos } \\
\text { Sim }\end{array}$ & 141 & 123 & 76 & 340 \\
Não & 113 & 41 & 35 & 189 \\
\hline $\begin{array}{l}\text { Percentual de } \\
\text { alunos Sim }\end{array}$ & 56 & & & \\
\multicolumn{1}{c|}{ São } & 44 & 75 & 68 & 64 \\
& & 25 & 32 & 36
\end{tabular}

Com a análise das respostas obtidas, verifica-se a utilização da caneca durável tanto em festas e/ou eventos quanto na universidade por parte dos entrevistados nas três áreas de estudo, mas ressalta-se que o uso para outros fins (festas e/ou eventos) é menor quando comparado ao uso realizado na universidade (Tabela 1). Isto reforça que a norma utilizada pelo restaurante foi 
efetiva, pois há alunos que as utilizam no ambiente institucional, mas que não as utilizam para outros fins.

Pode-se sugerir também que a adoção da caneca durável por essa parcela dos estudantes não é movida por sensibilização ambiental ou pela reflexão acerca das práticas de consumo, que corresponde ao segundo objetivo do projeto.

A caneca distribuída deveria estimular o usuário a incorporar a prática de redução no consumo (THALER, 2009), de modo que o uso seja uma ação natural, do dia a dia e sirva de estímulo para aquisição de outros hábitos que também possam contribuir com a redução do volume de resíduos gerados pela sociedade (PRADO et al., 2012).

É importante mencionar que, talvez, para boa parte dos alunos, o evento de entrega das canecas seja um dos primeiros contatos com a problemática ambiental da geração excedente de resíduos e que, para Soulé (1997), cada um de nós carrega consigo particularidades baseadas e moldadas por temperamento e educação.

Assim, faz-se indispensável a atuação da educação para orientar o consumo, cujo papel é relevante para a concepção de uma nova maneira de pensar (GOMES, 2006).

Relevante também é o processo contínuo de sensibilização ambiental e o estímulo para a adesão ao uso das canecas, havendo, então, a necessidade de campanhas continuadas (BARBOSA JUNIOR; KASSARDJIAN, 2015) e concomitantes com a articulação de todos os estabelecimentos presentes no campus.

Embora haja uma parcela discente que não faça uso da caneca, podemos verificar que, para a maioria dos estudantes, a aquisição das canecas UFSCar é significativa, pois firma seu ingresso na comunidade acadêmica e, supostamente, além da praticidade, representa um status. Assim, é possível que a caneca fornecida pelo projeto também seja vista como um objetosímbolo da universidade e que o seu uso para outros fins (festas e/ou eventos) seja uma possível identificação em relação ao grupo social e ao próprio projeto.

Foi verificado, pelas respostas obtidas na pergunta quatro, o tempo de uso da caneca distribuída pelo projeto. A Tabela 4 apresenta o tempo de uso e abandono. Observa-se que 439 alunos (83\%) fazem uso atual da caneca, destacando que, deles, 121 são ingressantes de 2016. Por sua vez, 90 entrevistados (17\%) não mais utilizam a caneca recebida e, desse grupo, 23 alunos não fazem uso de qualquer outra caneca.

Tabela 4 - Número e percentual de entrevistados por área acadêmica quanto ao uso atual e ao não uso da caneca durável após o recebimento nos eventos de entrega do Projeto Canecas, nos anos de 2010 a 2016

\begin{tabular}{|c|c|c|c|c|}
\hline \multicolumn{4}{|l|}{ 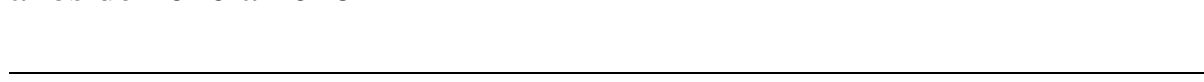 } & Total \\
\hline \multicolumn{5}{|l|}{ Uso atual } \\
\hline \multicolumn{4}{|l|}{$\begin{array}{l}\text { Número } \\
\text { percentual }\end{array}$} & $\begin{array}{l}439 \\
83\end{array}$ \\
\hline \multicolumn{5}{|c|}{ Não uso da caneca recebida } \\
\hline \multirow[t]{2}{*}{$\begin{array}{l}\text { Número } \\
\text { percentual }\end{array}$} & & & & $\begin{array}{l}90 \\
17\end{array}$ \\
\hline & $\begin{array}{l}\text { Área Ciências } \\
\text { Exatas e de } \\
\text { Tecnologia }\end{array}$ & $\begin{array}{l}\text { Área Ciências } \\
\text { Biológicas e da } \\
\text { Saúde }\end{array}$ & $\begin{array}{l}\text { Área Educação e } \\
\text { Ciências } \\
\text { Humanas }\end{array}$ & Total \\
\hline \multicolumn{4}{|c|}{ Alunos de 2010, 2011 e 2012 (de 4 a 6 anos de universidade) } & 149 \\
\hline
\end{tabular}


Uso atual

\begin{tabular}{|c|c|c|c|c|}
\hline Número & 45 & 50 & 12 & 107 \\
\hline Percentual & 30,2 & 33,5 & 8,1 & 71,8 \\
\hline \multicolumn{5}{|c|}{ Não uso da caneca recebida } \\
\hline Número & 24 & 15 & 3 & \\
\hline Percentual & 16,1 & 10,1 & 2 & \\
\hline \multicolumn{4}{|c|}{ Alunos de 2013 e 2014 (de 3 a 4 anos de universidade) } & 160 \\
\hline \multicolumn{5}{|l|}{ Uso atual } \\
\hline Número & 62 & 47 & 27 & 136 \\
\hline Percentual & 38,7 & 29,4 & 16,9 & 85 \\
\hline \multicolumn{5}{|c|}{ Não uso da caneca recebida } \\
\hline Número & 14 & 6 & 4 & \\
\hline Percentual & 8,7 & 3,8 & 2.5 & \\
\hline \multicolumn{4}{|c|}{ Alunos de 2015 (até 2 anos de universidade) } & 99 \\
\hline \multicolumn{5}{|l|}{ Uso atual } \\
\hline Número & 36 & 14 & 25 & 75 \\
\hline Percentual & 36,4 & 14,1 & 25,3 & 75,8 \\
\hline \multicolumn{5}{|c|}{ Não uso da caneca recebida } \\
\hline Número & 17 & 5 & 2 & \\
\hline Percentual & 17,1 & 5,1 & 2 & \\
\hline \multicolumn{4}{|c|}{ Alunos de 2016 ( 1 ano ou menos de universidade) } & 121 \\
\hline \multicolumn{5}{|l|}{ Uso atual } \\
\hline Número & 53 & 25 & 35 & 113 \\
\hline Percentual & 43,8 & 20,7 & 28,9 & 93,4 \\
\hline \multicolumn{5}{|c|}{ Não uso da caneca recebida } \\
\hline Número & 3 & 2 & 3 & \\
\hline Percentual & 2,5 & 1,6 & 2,5 & \\
\hline
\end{tabular}


A Tabela 4 mostra que, nas últimas sete edições do projeto, houve redução na adesão às canecas permanentes pelos estudantes da Área Ciências Biológicas e da Saúde, especialmente nos alunos com até dois anos de universidade. Todavia, é importante destacar também a adesão progressiva pelos alunos da Área Educação e Ciências Humanas, bem como a adesão dos alunos da Área de Ciências Exatas e Tecnologia ao longo das edições do projeto.

Foi possível identificar, mediante análise das respostas, que, dos 149 entrevistados ingressantes nos anos 2010, 2011 e 2012 das três áreas de conhecimento estudadas, 42 não usam mais a caneca recebida. Vale mencionar que, nos eventos de entrega desses anos, não houve alteração do caráter informativo, conforme descrito no item 1.2.1.

Entretanto, em 2012, houve a distribuição de canecas por uma imobiliária da cidade durante a semana de recepção dos calouros. Além disso, outras foram distribuídas por meio dos chamados "kits para os bixos", o que interferiu na procura das canecas do projeto pelos ingressantes que, consequentemente, não receberam informações sobre os objetivos do projeto e sobre seu papel na redução da geração de resíduos na UFSCar. Talvez o reduzido uso apresentado no período "de 4 a 6 anos de universidade" (71,8\%), quando comparado aos demais períodos, seja decorrente da distribuição prévia de canecas e da não participação de todos os alunos ingressantes no ano de 2012 nos eventos do projeto. Esse uso reduzido também pode ter relação com a vida útil da caneca que foi distribuída.

No ano de 2013, foi proposto um novo formato para os eventos de entrega das canecas, em comemoração aos dez anos de realização do projeto. O caráter informativo do evento foi mantido, mas houve a realização de uma exposição para a exibição de outros projetos, ações educativas e de gestão ambiental no âmbito da UFSCar; porém, apenas no campus São Carlos com a participação de grupos de estudo atuantes no mesmo sentido.

Em relação aos anos anteriores, em 2013 houve aumento considerável no número total de canecas distribuídas, de uma média de 1,5 mil para 2,5 mil nos campi São Carlos, Araras e Sorocaba.

Em 2014, a proposta original do evento foi mantida, contudo, foi realizado um pequeno questionário escrito com o objetivo de instigar maior reflexão acerca dos benefícios ambientais e econômicos do uso da caneca. Esse questionário era composto por quatro perguntas. Duas foram respondidas antes da apresentação do curta-metragem e, após sua exibição, foi solicitado aos participantes que respondessem às outras duas perguntas restantes. Houve um breve debate após a aplicação do questionário, permitindo uma discussão sobre o que foi abordado no evento pelo público participante.

Ressalta-se que as atividades realizadas nas instituições de ensino transformam os participantes em competentes agentes multiplicadores que influenciam positivamente as demais pessoas ao redor, familiares ou grupo de amigos e, assim, contribuem para a conscientização da sociedade (GRANZOTTO; PRETTO, 2012; LEITE, 2005). Desse modo, a inserção de tais atividades, como a aplicação de questionários ou a ocorrência de debates, é fundamental para estabelecer uma relação entre a comunidade estudantil e os problemas socioambientais existentes.

Pode-se inferir que a execução de outras atividades nos eventos dos anos de 2013 e 2014 se refletiu nos resultados apresentados, que correspondem a $85 \%$ do uso atual da caneca, quando comparado aos entrevistados dos demais períodos. Supõe-se que os alunos ingressantes nos anos mencionados se tornaram ainda mais sensibilizados e motivados no que tange à adoção da caneca permanente.

Em 2015, o formato do projeto foi mantido, entretanto, não foi possível atender a todos os novos integrantes da instituição devido a uma falha no processo de compras das canecas. Com isso, foram distribuídas as sobras da edição anterior do evento, atendendo parcialmente os ingressantes. Ainda assim, nota-se que o uso atual pelos ingressantes desses anos $(75,8 \%)$ é 
maior quando comparado ao resultado do período "de 4 a 6 anos de universidade" $(71,8 \%)$, quando parte dos estudantes não foi contemplada pelo evento de entrega.

Em 2016, o formato do projeto também se manteve. O resultado apresentado corresponde a 93,4\% do uso atual e pode se referir à aquisição recente da caneca. Os alunos ingressantes na instituição, sobretudo, devem ser estimulados constantemente no que tange à adoção da responsabilidade ambiental e à incorporação de novas atitudes, por exemplo, a utilização da caneca retornável tanto no campus quanto no ambiente extra-acadêmico.

Portanto, além de incluir a revisão de hábitos e outras práticas de redução e reutilização, é fundamental que as ações educativas desenvolvidas pela instituição contribuam para a construção de conhecimentos o mais próximo possível da realidade dos envolvidos, com o uso de abordagens que inspirem a visão crítica do mundo e a possibilidade de modificar o cotidiano e o seu significado no contexto sociocultural (LOGAREZZI, 2016).

É indispensável mencionar que, antes da implantação do projeto, o restaurante universitário do campus São Carlos utilizava, diariamente, mais de 2 mil unidades de copos plásticos nas suas refeições, segundo relato de funcionária, o que gerava cerca de $450 \mathrm{mil}$ resíduos anualmente. Um projeto semelhante foi implantado na Universidade de São Paulo no campus São Carlos -, em 2004, pelo Programa USP Recicla, que também reduziu a quantidade de copos descartáveis enviados anualmente para o aterro sanitário. Segundo estimativas, a redução foi de 500 mil unidades (UNIVERSIDADE DE SÃO PAULO, 2008).

A adoção da caneca durável contribui para a redução de resíduos plásticos descartáveis e, consequentemente, para a redução do volume de lixo e o aumento da vida útil dos aterros sanitários (XAVIER et al., 2006).

O objetivo da questão cinco foi verificar se a distribuição das canecas, associada ao evento de entrega, estimula a reflexão dos alunos acerca da problemática ambiental da geração de resíduos. Os resultados são apresentados pela Tabela 5 e observa-se que, para 462 entrevistados (87\%), o incentivo ao uso da caneca induziu tal reflexão. Em contrapartida, evidencia-se que 67 alunos (13\%) responderam que não se sentiram incentivados.

Tabela 5 - Número e percentual de entrevistados por área acadêmica em relação ao incentivo para o uso da caneca e consequente reflexão acerca dos resíduos gerados

\begin{tabular}{l|l|l|l|l|} 
& $\begin{array}{l}\text { Ciências } \\
\text { Exatas e de } \\
\text { Tecnologia }\end{array}$ & $\begin{array}{l}\text { Ciências } \\
\text { Biológicas } \\
\text { da Saúde }\end{array}$ & $\begin{array}{l}\text { Educação e } \\
\text { Ciências } \\
\text { Humanas }\end{array}$ & Total \\
\hline $\begin{array}{l}\text { Número de alunos } \\
\text { Sim }\end{array}$ & $\begin{array}{l}221 \\
\text { Não }\end{array}$ & 148 & 93 & 462 \\
Percentual de & & 16 & 18 & 67 \\
alunos & 87 & & & \\
Sim & 13 & 90 & 84 & 87 \\
Não & 10 & 16 & 13
\end{tabular}

É importante ressaltar que a formulação da questão pode ter induzido os participantes a responderem positivamente, refletindo nos resultados apresentados, devido às opções de respostas ou, ainda, por se tratar de uma questão ambiental na qual todos estão envolvidos e pela qual todos são responsáveis. Desse modo, seria importante investigar as razões que fizeram 
$13 \%$ dos participantes responderem não se sentiram estimulados, com o intuito de aprimorar ações referentes à conscientização ambiental.

A reflexão acerca de práticas de consumo, como a reutilização e a redução na geração de resíduos, é proposta apenas nos eventos de entrega das canecas, além do estímulo ao seu uso. O estímulo posterior depende unicamente do restaurante.

Embora as instituições de ensino superior sejam responsáveis, além da produção do saber crítico, pela mobilização dos indivíduos em defesa do ambiente e pela sustentação de uma articulação dos movimentos ambientalistas (SIQUEIRA, 2002), é fraca sua atuação nesse sentido. Pode-se evidenciar a ausência de vivência dos participantes em relação aos objetivos do projeto e à decorrente sensibilização ambiental proposta.

A realização de apenas uma palestra rápida com a exposição de um vídeo sobre o problema fornece informações fundamentais, mas não é suficiente para aguçar a percepção ambiental dos participantes.

Logo, é necessário tornar o espaço do evento propício ao debate e à percepção das diferentes opiniões e visões dos alunos envolvidos, evocando emoções e desejos, transformando a experiência em uma lembrança aprazível e significativa. Por meio do diálogo e da tematização do meio ambiente como sendo o espaço, a residência e parte da vida do indivíduo, é que o saber ambiental se faz pertinente (MAKIUCHI, 2011).

Desta maneira, nos eventos de entrega das canecas, deve-se incluir imagens, informações atualizadas, interação e dinamismo, estabelecendo um vínculo do aluno com a instituição, com os demais participantes e com o projeto. Essas são as experiências chamadas de experiências de pico por Soulé (1997), que são responsáveis por deixar lembranças vívidas capazes de realizar a modificação nos modos pessoais e estabelecer conexões ambientais vitalícias.

Além disso, outros meios de divulgação e estímulo para a adoção da caneca retornável e para a decorrente aquisição de sensibilização ambiental poderiam ser utilizados constantemente pela instituição, como faixas, quadros informativos, banners, exposições e até mesmo a continuidade dos objetivos do projeto por meio de outros eventos educativos, durante os semestres letivos.

Deste modo, as ações de EA a serem realizadas, que poderiam contar com a participação dos grupos estudantis Gire e EMA-BIO nas suas execuções, conseguiriam alcançar os alunos que não puderam estar presentes nos eventos de entrega. Elas reforçariam, assim, a reflexão acerca de novas atitudes e a construção de conhecimentos mais próximos da realidade, assim como uma visão crítica do mundo, em consonância com Logarezzi (2016).

É necessária também a formação de um fórum permanente de discussão na UFSCar no que tange a questões sociais, políticas e econômicas relacionadas à prática da EA crítica.

O Grupo de Estudos e Pesquisas em Educação Ambiental, Diversidade e Sustentabilidade (GEPEADS) da Universidade Federal Rural do Rio de Janeiro (UFRRJ) é um modelo bem-sucedido a ser citado. Criado em 2003, ele partiu de discussões teóricas responsáveis por fundamentar a prática e possui como identidade a convergência ensinopesquisa-extensão, produzindo pesquisas que acompanham processos de formação, desenvolvendo atividades para a formação de educadores ambientais de atuação formal e não formal, realizando cursos, seminários e executando projetos de extensão universitária, cuja intervenção se dá na universidade e comunidade externa (SOARES; GUIMARÃES; OLIVEIRA, 2009).

Embora indubitavelmente apresente limitações, o Projeto Canecas é uma ação exemplar, importante e positiva tanto para a instituição quanto para a comunidade estudantil participante. O acompanhamento constante das propostas apresentadas é fundamental para identificar as dificuldades e as resistências presentes no processo e garantir a efetividade do projeto ao longo de suas edições. 


\subsection{O Programa Coleta Seletiva Solidária UFSCar}

Na UFSCar, os resíduos gerados nos departamentos e prédios de salas de aula são coletados pelos profissionais da limpeza, acondicionados em sacos plásticos azuis ou esverdeados para diferenciá-los dos resíduos comuns e depositados nos contentores azuis até serem coletados pelas cooperativas de catadores. Em virtude das atividades de formação ambiental e dos treinamentos semestrais realizados pelo Programa com esses trabalhadores, há uma eficiente colaboração na correta separação e acondicionamento dos recicláveis.

Os outros materiais recicláveis depositados nos contentores são provenientes das lanchonetes e do restaurante universitário. Os membros da comunidade acadêmica e, por vezes, membros externos também utilizam esses contentores para o descarte de materiais. Na maioria das vezes, a intenção é dar correto destino aos materiais recicláveis.

Em 21 meses dos anos de 2015 e 2016, foram coletadas 64.419 toneladas de resíduos recicláveis, como papéis, embalagens plásticas e papelão provenientes dos departamentos e prédios de salas de aula do Campus São Carlos. Entretanto, em algumas ocasiões, não foi realizada a coleta ou a pesagem desses resíduos. Assim, supõe-se que a quantidade de resíduos retirada no campus seja superior à apresentada, tornando o programa, nesse sentido, uma referência para as demais instituições de ensino superior pelo seu impacto socioambiental.

Programas de coleta seletiva de outras IES, como o da Universidade Tecnológica Federal do Paraná (UTFPR) e da Universidade de São Paulo (USP), são exemplos de sucesso que merecem destaque.

$\mathrm{Na}$ UTFPR, campus Londrina, os trabalhos em relação à coleta seletiva solidária consideram cinco fases em seu processo de condução: diagnóstico, planejamento, implantação, monitoramento e avaliação dos resultados do monitoramento. Houve a formação de uma pequena Comissão de Gestão de Resíduos Sólidos composta por docentes, servidores e estagiários (DAL BOSCO; PRATES, 2017).

As atribuições da comissão são o monitoramento da qualidade da segregação e a contribuição para a atualização do programa de gestão de resíduos, além da sensibilização da comunidade do campus, que ocorre por meio de diversas estratégias de EA: abordagem pessoal da comunidade universitária interna (nas seções administrativas, corredores, salas de aula, fila do RU); treinamentos com servidores; banners, pôsteres e murais itinerantes atualizados frequentemente; redes midiáticas (Facebook, SnapChat, Instagram, página na web e TVs do campus); adesivos nos banheiros e restaurante universitário; recepção de calouros e ações solidárias semestrais, dentre outras abordagens (DAL BOSCO; PRATES, 2017; YOSHIDA, 2016).

É também de suma importância a divulgação dos resultados do monitoramento, campanhas e ações desenvolvidas para o público envolvido, dando-lhes o retorno do trabalho que está sendo realizado, além da coleta de opinião pública (DAL BOSCO; PRATES, 2017).

Ainda de acordo com Yoshida (2016), as intervenções contínuas e permanentes realizadas pela Comissão, com destaque para as ações solidárias de construção de ambientes de convivência universitária, resultaram num maior alcance da comunidade acadêmica, em termos de conhecimento e participação no programa.

Após o sucesso da implantação da coleta seletiva, sucedeu-se a elaboração de um manual que relata a experiência do campus Londrina, servindo de orientação e inspiração para outras instituições. O livro está disponível para download gratuito nas principais lojas digitais (Kobo, iTunes, Amazon e Google Play).

Em relação à USP, o programa de gestão de resíduos USP Recicla ocorre em todos os campi da instituição (LEME; MARTINS; BRANDÃO, 2012), valendo frisar que cada campus possui as chamadas comissões de unidade ou órgãos. Elas articulam, planificam e desenvolvem 
práticas locais nas instâncias educacionais e administrativas técnicas, sendo compostas por docentes, discentes, funcionários, departamentos e unidades (MENEZES, 2014).

Em São Carlos, nos últimos quinze anos, foram desenvolvidas diversas atividades educativas, como reuniões, encontros e palestras, dialogando acerca dos princípios, estrutura e função do Programa da USP e buscando a sensibilização, a motivação e o fornecimento de ferramentas para a comunidade acadêmica, de modo a favorecer a execução das ações individuais e coletivas. Projetos de intervenção educativa realizados no ambiente institucional e comunitário externo (na moradia estudantil e nas escolas do ensino fundamental e médio), apoiados pelos docentes das diversas unidades de ensino, da Pró-Reitoria de Cultura e Extensão e da Superintendência de Gestão Ambiental. Também há a formação ambiental dos discentes da graduação (com a realização de minicursos, reuniões semanais para estudo e planejamento de ações, incentivos para a apresentação do projeto em eventos científicos técnicos, entre outros) (LEME; MARTINS; BRANDÃO, 2012).

São sete as comissões da USP campus São Carlos trabalhando de acordo com o processo de gestão compartilhada e integrada. Elas são formadas pelos Institutos de Química (IQSC), de Física (IFSC), de Ciências Matemáticas e Computação (ICMC), de Arquitetura e Urbanismo (IAU), além da Prefeitura do Campus (PUSP-SC) e dos Centros de Divulgação, Ciência e Cultura (CDCC) e de Informação de São Carlos (CISC). Importante mencionar também que são realizadas reuniões entre a coordenação e as comissões para a exposição dos entraves e as possíveis intervenções para a resolução (MENEZES, 2014).

Ainda segundo Menezes (2014), a atuação da comunidade acadêmica é fundamental para a boa manutenção do processo de gestão de resíduos.

Como estagiária do DeAEA, auxiliei no desenvolvimento e na organização de atividades educativas e acompanhei as dificuldades cotidianas enfrentadas na manutenção das atividades realizadas pelo departamento, cujo objetivo sempre foi envolver a comunidade acadêmica, sensibilizando quanto ao consumo e à problemática da geração de resíduos.

A maior dificuldade a ser destacada neste trabalho é quanto à participação da comunidade acadêmica. Verifica-se a má utilização dos equipamentos fornecidos pelo programa para a coleta dos resíduos. Além disso, há danos e extravios, bem como a retirada desses materiais, como as caixinhas coletoras de papel. A Figura 1 mostra a utilização de uma dessas caixinhas coletoras como assento, na área externa de um departamento do campus.

Figura 1 - Uso da caixinha coletora de papel como assento

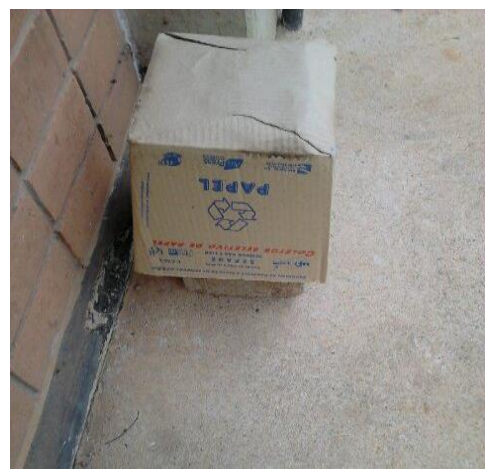

Foto: Priscila Luiza Cardoso.

No que tange aos contentores azuis, também são utilizados erroneamente para o descarte de resíduos orgânicos que nem sempre são gerados dentro do campus, assim como resíduos unitários, ou seja, não acondicionados previamente em sacos plásticos. Resíduos de laboratório 
de origem biológica infectante, como maravalha (aparas de madeira utilizada nos experimentos com camundongos), também são descartados nesses equipamentos.

Assim, tais contentores frequentemente são encontrados em condições insalubres e precárias, havendo odor, sujeira, proliferação de organismos decompositores e vetores de doença. É de se destacar que o mau uso de contentores é um problema presente na UFSC, segundo Pitsch (2011), e que também não conta com a colaboração/participação da comunidade acadêmica no processo de gestão. Para que as ações educativas possam ter alcance mais efetivo na UFSCar, verifica-se a necessidade de implantação de uma política institucional que possa efetivamente apoiar o programa, ampliando o envolvimento formal da comunidade, e de maior investimento em termos de recursos humanos e materiais.

\subsubsection{Semana do Lixo Mínimo e a Feira de Trocas}

A proposta da reciclagem, para Siqueira (2002), é a recuperação dos materiais descartados e a modificação de suas características físicas. Ele não é uma solução ecológica efetiva, pois pode representar a ausência de responsabilidade no consumo, e deve ser empregado somente quando não for possível praticar a redução e/ou a reutilização. Sendo assim, além de seguir a determinação federal através do Decreto $\mathrm{n}^{\circ}$ 5.9540/2006, conforme citado no item 1.2.2., outras ações, como a Feira de Trocas, têm sido realizadas para que no âmbito educativo a coleta seletiva não seja considerada uma solução única na instituição.

Assim, com o objetivo de despertar na comunidade estudantil a reflexão para a geração excedente de resíduos, decorrentes de um consumo não consciente, foram desenvolvidas as atividades da $1^{\text {a }}$ Semana do Lixo Mínimo e a Feira de Trocas.

$\mathrm{Na}$ primeira atividade, houve a participação de apenas dezessete estudantes, embora divulgada pessoalmente e por meio da rede social, além de cartazes fixados pelo campus. Vale destacar, todavia, que o evento coincidiu com o período de greve dos servidores institucionais e que tal situação pode ter interferido no desenvolvimento da atividade.

Dessa maneira, podemos ressaltar que as questões administrativas, de disponibilidade de recursos humanos e/ou financeiros, além da prioridade que se atribui à questão ambiental, intervêm no desenvolvimento de atividades e iniciativas.

Podemos citar novamente o Programa USP Recicla de São Carlos que, desde a implantação em 1995, teve sua gestão afetada por alterações na política institucional; o confronto com os entraves mostrou aos participantes do programa a importância de atuarem de forma flexível, permanecendo atentos às possíveis alterações nas questões administrativas e realizando a adaptação nos procedimentos operacionais mesmo em situações de ausência de recursos financeiros. Neste caso, por exemplo, realizando ações pontuais, como a difusão de novas práticas de reutilização e reciclagem de materiais, bem como a ocorrência de cursos e palestras de sensibilização/conscientização. Sendo a escassez de recursos um problema visível em outras instituições de ensino superior, a experiência deste programa é um bom exemplo a ser mencionado (MENEZES, 2014).

Em relação à ocorrência da Feira de Trocas, desde a sua idealização na $1^{a}$ Semana do Lixo Mínimo, não conta com participação expressiva da comunidade acadêmica.

Por meio da aplicação do segundo questionário, foram entrevistados 66 estudantes dos cursos de graduação da instituição. A Tabela 6 apresenta o resultado, no que tange aos eventos mencionados.

Tabela 6 - Respostas dos entrevistados em relação à participação nos eventos de educação ambiental na UFSCar, campus São Carlos 
$1^{\text {a }}$ Semana do Lixo Mínimo

\begin{tabular}{l|l}
\hline Não compareci, pois não vi a divulgação & 42 \\
\hline $\begin{array}{l}\text { Não compareci, pois não me interessei pelo } \\
\text { assunto }\end{array}$ & 9 \\
\hline Não compareci devido ao horário (ruim) & 8 \\
\hline $\begin{array}{l}\text { Acho este tipo de evento importante, mas } \\
\text { não me interesso pelo assunto }\end{array}$ & 7 \\
\hline
\end{tabular}

Feira de Trocas

\begin{tabular}{l|l}
\hline Não compareço, pois não vejo a divulgação & 14 \\
\hline $\begin{array}{l}\text { Não compareço, pois não me interesso pelo } \\
\text { assunto }\end{array}$ & 13 \\
\hline $\begin{array}{l}\text { Não compareço devido ao horário e/ou dia } \\
\text { (ruim) }\end{array}$ & 9 \\
\hline $\begin{array}{l}\text { Acho este tipo de evento importante, mas } \\
\text { não me interesso pelo assunto }\end{array}$ & 19 \\
\hline Participo quando possível & 11 \\
\hline Entrevistados & 66
\end{tabular}

Embora com reduzido número de participantes, verifica-se que somente a utilização da rede social ou dos cartazes na divulgação de ambas as atividades não foi eficaz, pois 42 alunos, em relação à $1^{\text {a }}$ Semana do Lixo Mínimo, e quatorze alunos, no que tange à Feira de Trocas, relataram não comparecer por não terem sido contemplados com a divulgação.

Pode-se observar, também, que uma parcela dos entrevistados não se interessa pelos assuntos abordados nesses eventos. Em relação à $1^{\text {a }}$ Semana do Lixo Mínimo, são nove alunos. Há outros sete alunos que também não se interessam, entretanto, consideram esse tipo de evento importante. No que tange à Feira de Trocas, são treze os alunos desinteressados pelo assunto e outros dezenove que, embora desinteressados, consideram o evento importante.

É interessante mencionar que atividades desse tipo no campus proporcionam o convívio construtivo entre os participantes, favorecendo a discussão e a troca de ideias acerca de diversos assuntos, sobretudo os ambientais. Partindo-se de tal pressuposto, é possível motivar a participação estudantil, frisando na divulgação a oportunidade de interação social que o espaço pode fornecer.

Vale ressaltar, contudo, que a ocorrência da $1^{\text {a }}$ Semana do Lixo Mínimo possibilitou ao público participante maior contato com a problemática socioambiental da geração de resíduos, inclusive as dificuldades enfrentadas pela instituição em relação à manutenção de ações neste sentido, destacando a possibilidade de um novo modo de vida compatível com o desenvolvimento e a conservação do meio ambiente. O evento poderia ser acoplado a outras atividades institucionais, como a Feira de Ciências, a Calourada e a Semana do Meio Ambiente.

\section{Considerações finais}

A nossa percepção ambiental é baseada em três dimensões: experiencial, analítica e valorativa. É necessário que os eventos de entrega das canecas UFSCar, contemplando tais dimensões, sejam dinâmicos, interativos e atualizados, estabelecendo um vínculo dos envolvidos com a instituição, com os demais participantes e com os objetivos propostos pelo 
Projeto Canecas. Este espaço deve ser propício ao debate e à percepção das diversas opiniões e visões dos participantes, de modo a tornar a experiência uma lembrança aprazível e significativa.

O estímulo para o uso da caneca e para a aquisição de percepção ambiental deve ser constante durante os semestres letivos, de maneira a evocar emoções e desejos nos envolvidos. Além disso, é também primordial a realização de atividades de formação e sensibilização ambientais no que tange ao funcionamento adequado da coleta seletiva no campus, que deve envolver a comunidade acadêmica e as cooperativas de catadores com o objetivo de motivar sua atuação, reforçando seu papel e valor tanto para a sociedade quanto para a universidade. Faz-se necessário, neste sentido, a articulação de todas as unidades instaladas no campus para a efetuação deste sistema de gestão ambiental através de uma política específica.

É fundamental a formação de um fórum permanente de discussão sobre questões sociais relacionadas à prática da EA crítica no campus, indo além da problemática da geração de resíduos sólidos e compreendendo informações históricas e subjetivas.

A construção do conhecimento a partir da realidade de todos os atores e atrizes envolvidos nas atividades deve incluir abordagens críticas ao sistema no qual estamos inseridos a partir das experiências cotidianas, o resgate e a edificação de saberes, bem como o desenvolvimento de intervenções educativas responsáveis por fomentar um cuidado que seja norteador de todas as ações e voltado a uma sensibilização que contemple todos os âmbitos da nossa vida.

Destaca-se que as práticas desenvolvidas pela instituição constituem importantes contribuições para as questões socioambientais. Em relação ao Projeto Canecas, cuja adesão pela comunidade estudantil é majoritária, corresponde à redução da geração de resíduos no ambiente acadêmico.

No que tange ao Programa de Coleta Seletiva do campus, coopera com a economia solidária local e com a qualidade do meio ambiente ao reduzir o envio de resíduos para o aterro sanitário municipal.

Assim sendo, o acompanhamento constante de tais ações é elementar para identificar as dificuldades e as resistências presentes nos processos, de maneira a garantir a efetividade das ações da instituição em relação à formação ambiental de toda a comunidade acadêmica.

\section{Referências}

BARBOSA JUNIOR, W. G.; KASSARDJIAN, P. P. C. Programa de gestão de resíduos em escola pública: Poli USP Recicla. Fórum Ambiental da Alta Paulista, Tupã, v. 11, n. 8, p. 166-172, 2015. Disponível em: https://bit.ly/2qfurZL. Acesso em: 5 maio 2017.

BRASIL. Conselho Nacional do Meio Ambiente. Resolução Conama no 275, de 25 de abril de 2001. Estabelece o código de cores para os diferentes tipos de resíduos, a ser adotado na identificação de coletores e transportadores, bem como nas campanhas informativas para a coleta seletiva. Diário Oficial da União: seção 1, Brasília, DF, n. 117-E, p. 80, 19 jun. 2001.

BRASIL. Decreto ${ }^{\circ}$ 5.940, de 25 de outubro de 2006. Institui a separação dos resíduos recicláveis descartados pelos órgãos e entidades da administração pública federal direta e indireta, na fonte geradora, e a sua destinação às associações e cooperativas dos catadores de materiais recicláveis, e dá outras providências. Diário Oficial da União: seção 1, Brasília, DF, 26 out. 2006.

BRASIL. Ministério do Meio Ambiente. Lei $\mathrm{n}^{\circ}$ 12.305, de 2 de agosto de 2010. Institui a Política Nacional de Resíduos Sólidos; altera a Lei $\mathrm{n}^{\circ}$ 9.605, de 12 de fevereiro de 1998; e dá outras providências. Diário Oficial da União: seção 1, Brasília, DF, 3 ago. 2010. 
CARVALHO, I. C. M. Educação ambiental crítica: nomes e endereçamento da educação. In: BRASIL. Ministério do Meio Ambiente. Identidades da educação ambiental brasileira. Brasília, DF: Ministério do Meio Ambiente, 2004. p. 13-24. Disponível em: https://bit.ly/2OWym8p. Acesso em: 19 set. 2016.

DAL BOSCO, T. C.; PRATES, K. V. M. C. Manual para a instalação e manutenção da coleta seletiva solidária: a experiência da UTFPR Campus Londrina. Jundiaí: Paco Editorial, 2017.

FERREIRA, L. C. Sustentabilidade: uma abordagem histórica da sustentabilidade. In: BRASIL. Ministério do Meio Ambiente. Encontros e caminhos: formação de educadoras(es) ambientais e coletivos educadores. Brasília, DF: Ministério do Meio Ambiente, 2005. p. 315-321.

GOMES, D. V. Educação para o consumo ético e sustentável. REMEA, Rio Grande, v. 16, p. 18-31, 2006. Disponível em: https://bit.ly/2BkNHY0. Acesso em: 31 jan. 2018.

GOUVEIA, N. Resíduos sólidos urbanos: impactos socioambientais e perspectiva de manejo sustentável com inclusão social. Ciência \& Saúde Coletiva, Rio de Janeiro, v. 17, n. 6, p. 1503-1510, 2012. Disponível em: https://bit.ly/2VLc0bj. Acesso em: 15 out. 2016.

GRANZOTTO, M. M.; PRETTO, V. A cultura da sustentabilidade: entre fazeres e saberes. In: JORNADA NACIONAL DA EDUCAÇÃO, 16., 2012, Santa Maria. Anais [...]. Santa Maria: Unifra, 2012. p. 1-7. Disponível em: https://bit.ly/33DH4MN. Acesso em: 16 ago. 2016.

GUIMARÃES, R. P.; FONTOURA, Y. S. R. Rio + 20 ou Rio - 20? Crônica de um fracasso anunciado. Ambiente \& Sociedade, São Paulo, v. 15, n. 3, p. 19-39, 2012. Disponível em: https://bit.ly/2OUaulQ. Acesso em: 16 ago. 2016.

HEMPE, C.; NOGUERA, J. O. C. A educação ambiental e os resíduos sólidos. Revista Eletrônica em Gestão, Educação e Tecnologia Ambiental, Santa Maria, v. 5, n. 5, p. 682-695, 2012. Disponível em: https://bit.ly/2Mi7Ggm. Acesso em: 17 out. 2016.

JACOBI, P. Educação e meio ambiente: transformando as práticas. Revista Brasileira de Educação Ambiental, Brasília, DF, n. 0, p. 28-35, 2004. Disponível em: https://bit.ly/32mwNEz. Acesso em: 16 maio 2016.

LEITE, T. M. C. Entraves espaciais: brownfields caracterizados por aterros de resíduos sólidos urbanos desativados no município de São Paulo/SP. 2005. 146 f. Tese (Doutorado em Geografia) - Instituto de Geociências e Ciências Exatas, Universidade Estadual Paulista, Rio Claro, 2005

LEME, P. S.; MARTINS, J. L. G.; BRANDÃO, D. (Orgs.). Guia prático para minimização e gerenciamento de resíduos: USP São Carlos. São Carlos: USP São Carlos, 2012. Disponível em: https://bit.ly/35C5yI2. Acesso em: 7 fev. 2018.

LOGARREZI, A. Educação ambiental em resíduo: uma proposta de terminologia. In: CINQUETTI, H. C. S.; LOGARREZI, A. (Orgs.). Consumo e resíduo: fundamentos para o trabalho educativo. São Carlos: EdUFSCar, 2016. p. 85-115.

MAKIUCHI, M. F. R. Alteridade. In: BRASIL. Ministério do Meio Ambiente. Encontros e caminhos: formação de educadoras(es) ambientais e coletivos educadores. Brasília, DF: Ministério do Meio Ambiente, 2005. p. 29-35.

MAKIUCHI, M. F. R. Alteridade e educação ambiental. Pesquisa em Educação Ambiental, Rio Claro, v. 6, n. 1, p. 85-99, 2011. Disponível em: https://bit.ly/32njwvd. Acesso em: 17 mar. 2016.

MENEZES, C. M. V. M. C. Gestão de resíduos sólidos em instituições de ensino superior: o Programa USP Recicla no campus de São Carlos. 2014. 96 f. Dissertação (Mestrado em Gestão Ambiental e 
Sustentabilidade) - Universidade Nove de Julho, São Paulo, 2014. Disponível em: https://bit.ly/2nPEx2H. Acesso em 12 dez. 2017.

PITSCH, E. F. A gestão de resíduos sólidos na UFSC e sua adequação frente às novas regras da Política Nacional de Resíduos Sólidos (lei 12.305/2010). 2011. Trabalho de Conclusão de Curso (Bacharelado em Agronomia) - Centro de Ciências Agrárias, Universidade Federal de Santa Catarina, Florianópolis, 2011.

PORTO-GONÇALVES, C. W. A globalização da natureza e a natureza da globalização. Rio de Janeiro: Civilização Brasileira, 2006.

PRADO, P. F.; BARRETO, M. A.; BERTUSO, P. C.; BUSICO, S. U.; PINDOBEIRA, D. A.; GALDIANO, C. M. R.; PRINTES, L. B. O projeto de minimização de resíduos sólidos na UFSCar: o Projeto Canecas. Revista Ciência em Extensão, Rio Claro, v. 8, n. 3, p. 258-261, 2012. Disponível em: https://bit.ly/2IUBYE3. Acesso em: 17 out. 2016.

A COLETA SELETIVA E AS AÇÕES DE EDUCAÇÃO AMBIENTAL. Departamento de Apoio à Educação Ambiental, São Carlos, 2014. Disponível em: <http://www.deaea.ufscar.br/projetos-deextensao-1/a-coleta-seletiva-e-as-acoes-de-educacao-ambiental>. Acesso em: 17 maio 2016.

RAMOS, J. S; DELL'ISOLA, J. A. P. Gestão integrada de resíduos sólidos em instituições de ensino: estudo de caso para aplicação nas Faculdades Kennedy. Resíduos em Referência, Belo Horizonte, n. 1, p. 10-15, 2010. Disponível em: https://bit.ly/2Mlze4z. Acesso em: 17 set. 2016.

SIQUEIRA, L. C. Produção de resíduos no restaurante universitário: diagnósticos para ações de educação ambiental no programa Agenda 21 da Universidade de Brasília. 2002. 128 f. Dissertação (Mestrado em Ecologia) - Universidade de Brasília, Brasília, DF, 2002.

SOARES, A. M. D.; GUIMARÃES, M.; OLIVEIRA, L. M. T. Grupo de estudos e pesquisa em educação ambiental, diversidade e sustentabilidade: GEPEADS/UFRRJ. Ambiente \& Educação, Rio Grande, v. 14, n. 2, p. 101-108, 2009. Disponível em: https://bit.ly/32mExq7. Acesso em: 2 fev. 2018.

SOBARZO, L. C. D.; MARIN, F. A. D. M. Resíduos sólidos: representações, conceitos e metodologias: propostas de trabalho para o ensino fundamental. Revista de Ensino de Geografia, Uberlândia, v. 1, n. 1, p. 3-14, 2010. Disponível em: https://bit.ly/33CHNOm. Acesso em: 18 mar. 2016.

SOULÉ, M. E. Mente na biosfera; mente da biosfera. In: WILSON, E. O. (Org.). Biodiversidade. Rio de Janeiro: Nova Fronteira, 1997. p. 593-598.

SPAZZIANI, M. L; GONÇALVES, M. F. C. Construção do conhecimento. In: BRASIL. Ministério do Meio Ambiente. Encontros e caminhos: formação de educadoras(es) ambientais e coletivos educadores. Brasília, DF: Ministério do Meio Ambiente, 2005. p. 105-114.

TAUCHEN, J.; BRANDLI, L. L. A gestão ambiental em instituições de ensino superior: modelo para implantação em campus universitário. Gestão \& Produção, São Carlos, v. 13, n. 3, p. 503-515, 2006. Disponível em: https://bit.ly/2BjSGZk. Acesso em: 10 out. 2016.

THALER, R. A caneca ecológica. ENIAC, Guarulhos, v. 1, n. 1, p. 33-34, 2009.

UNIVERSIDADE FEDERAL DE SÃO CARLOS. Estatuto da Universidade Federal de São Carlos. São Carlos: UFSCar, 1990. Disponível em: https://bit.ly/2OQkBI1. Acesso em: 15 maio 2016.

UNIVERSIDADE FEDERAL DE SÃO CARLOS. Relatório anual de atividades 2010. São Carlos: UFSCar, 2011. Acesso em: 15 mar. 2016. 
UNIVERSIDADE FEDERAL DE SÃO CARLOS. Relatório anual de atividades 2011. São Carlos: UFSCar, 2012. Acesso em: 15 mar. 2016

UNIVERSIDADE FEDERAL DE SÃO CARLOS. Relatório anual de atividades 2012. São Carlos: UFSCar, 2013. Acesso em: 18 mar. 2016.

UNIVERSIDADE FEDERAL DE SÃO CARLOS. Relatório anual de atividades 2013. São Carlos: UFSCar, 2014. Acesso em: 18 mar. 2016

UNIVERSIDADE FEDERAL DE SÃO CARLOS. Relatório anual de atividades 2014. São Carlos: UFSCar, 2015. Acesso em: 20 mar. 2016.

UNIVERSIDADE FEDERAL DE SÃO CARLOS. Relatório anual de atividades 2015. São Carlos: UFSCar, 2016. Acesso em: 20 mar. 2016.

UNIVERSIDADE DE SÃO PAULO. Relatório anual 2007: projeto educativo para minimização de resíduos sólidos para o restaurante universitário do campus de São Carlos. São Carlos: USP São Carlos, 2008. Disponível em: <file:///C:/Users/tE/Downloads/2007simpep_fernanda_pazu_talita_taiwo.pdf>. Acesso em: 17/10/2016

YOSHIDA, S. E. Efetividade da coleta seletiva solidária para alunos de graduação da UTFPR Londrina: aspectos ambientais e de sensibilização. 2016. Trabalho de Conclusão do Curso (Bacharelado em Engenharia Ambiental) - Universidade Tecnológica Federal do Paraná, Londrina, 2016. Disponível em: https://bit.ly/35Ep7zj. Acesso em: 5 fev. 2018.

XAVIER, L. H.; CARDOSO, R.; MATOS, R. M.; ADISSI, P. J. Legislação ambiental sobre destinação de resíduos sólidos: o caso das embalagens plásticas pós-consumo. In: SIMPEP, 13., 2006, Bauru. Anais [...]. Bauru: Unesp, 2006. Disponível em: https://bit.ly/2BiDiwa. Acesso em: 5 out. 2016. 